American Journal of Applied Sciences 6 (9): 1682-1689, 2009

ISSN 1546-9239

(C) 2009 Science Publications

\title{
Interface Micromotion of Cementless Hip Stems in Simulated Hip Arthroplasty
}

\author{
${ }^{1,2}$ Mohammed Rafiq Abdul Kadir and ${ }^{2}$ Nazri Kamsah \\ ${ }^{1}$ Medical Implant Technology Group, Faculty of Biomedical Engineering and Health Sciences, \\ University Technology Malaysia, 81310 UTM Skudai, Johor, Malaysia \\ ${ }^{2}$ Faculty of Mechanical Engineering, \\ University Technology Malaysia, 81310 UTM Skudai, Johor, Malaysia
}

\begin{abstract}
Problem statement: The design of hip prostheses has evolved over time due to various complications found after hip replacement surgery. The currently commercially available cementless femoral stems can be categorized into one of three major types, straight cylindrical, tapered rectangular and anatomical. Each type proposes a unique concept to achieve primary stability-a major requirement for bone healing process. Virtual analyses have been made on individual implants, but comparison between the three major types is required to determine the strength and weaknesses of the design concepts. Approach: Three types of implants were modeled in three dimensions-the straight cylindrical, rectangular taper and anatomical. The size of the three implants was carefully designed to fit and fill the canal of a femur reconstructed from a computed tomography image dataset. Hip arthroplasty was simulated virtually by inserting the hip stem into the femoral canal. Finite element method was used in conjunction with a specialized sub-routine to measure micromotion at the boneimplant interface under loads simulating physiological walking and stair-climbing. Another subroutine was used to assign bone properties based on the grayscale values of the CT image. Results: All the three types of cementless hip stems were found to be stable under both walking and stair climbing activities. Large micromotion values concentrated around the proximal and distal part of the stems. Conclusion/Recommendations: The three major types of hip stems were compared in this study and all of them were found to be stable after simulated physiological activities.
\end{abstract}

Key words: Hip stem design, hip joint replacement, cementless stem, finite element analysis

\section{INTRODUCTION}

Cementless hip stems come in different shapes and sizes. In order to analyze practically the effect of these different geometries on primary stability, they should be grouped into several categories based on their features. There is no consensus at the moment in terms of grouping cementless stems according to their geometry, mostly due to the large variety of cementless stems available in the market. Healy ${ }^{[1]}$ grouped cementless femoral components into 5 basic types with examples of each-the cylindrical distal filling (the AML, the solution), the anatomic, proximal fit and fill (the PCA, the anatomic), combination (the SROM, the bridge), dual, tapered wedge (the Omnifit, the Summit) and flat, tapered wedge (the Tri-Lock, the Accolade). Mallory et al. ${ }^{[2]}$ grouped them into three distinct design geometries and philosophies-the extensive porous coating with distal fixation (the AML), the anatomic proximal fixation (the PCA, the Anatomic) and gradual proximal to distal off-loading tapered geometry (the Mallory-Head).

From the search in the literature and websites of implant manufacturers, similar groupings to Mallory et $a l .{ }^{[2]}$ was found based on the overall geometry. The first group belongs to hip stems which are not tapered in any plane in the distal half with cylindrical shape. Examples of hip stems within this group are the AML (DePuy) and the Versys (Zimmer). The second grouping is based on stems that have a proximal to distal taper in either or both the sagittal and longitudinal planes such as the Alloclassic (Zimmer) and the Triloc (DePuy). Some tapered designs such as the Mallory-Head also have a posteriorto-anterior taper in the coronal plane ${ }^{[2]}$. The third group is the Anatomic and was defined as stems designed

Corresponding Author: Mohammed Rafiq Abdul Kadir, Medical Implant Technology Group,

Faculty of Biomedical Engineering and Health Sciences, University Technology Malaysia,

81310 UTM Skudai, Johor, Malaysia Tel: +6075535961 Fax: +6075535430

1682 
with an anterior-posterior curve that mimics the natural curve of the human femur. The design therefore has a unique left and right component. Some examples of the anatomical stem are the ABG (Stryker) and the IPS (DePuy). All the three groups were categorized based on the overall geometry of the implant. Micro and macro features on the surface of the implant were ignored in the grouping.

Most cementless femoral stems rely on fixation based on press-fit where there is a contact pressure between the bone and the implant. However, due to the viscoelastic behavior of bone the effectiveness of pressfit is limited through relaxation of contact pressures at the interface ${ }^{[3]}$. The straight cylindrical stems normally rely on strong cortical support distally for stability, however, there are reports where fixation could be achieved proximally ${ }^{[4]}$. The tapered stems usually rely on a three-point fixation pattern and a gradual offloading distally ${ }^{[5]}$. Fixation can also be achieved proximally, such as the CLS stem (Zimmer), or distally, such as the Alloclassic (Zimmer). The curvature in anatomical stems provides maximum contact with the endosteal bones and sometimes with a large proximal segment to match the proximal cavity of the femur. It has been claimed that this design feature optimized resistance to axial, bending and rotational forces ${ }^{[6]}$. Fixation for the anatomical stems can also be achieved either proximally or distally. The ABG (Stryker) and the IPS (DePuy) has a smaller stem diameter distally suggesting an intended proximal fixation through distal bone overreaming technique. The Profile (DePuy), however, has a standard diameter of stem distally which can be regarded as distally fixed.

\section{MATERIALS AND METHODS}

Three implant designs to represent each group were modeled using a commercially available three dimensional modeling software. A generic straight cylindrical stem was developed to represent the first group with a geometry similar to the AML (DePuy). For the tapered group, another hip stem model was developed based on the overall geometry of the Alloclassic (Zimmer). It has a flat straight taper in transverse section and a wedge shape mediolaterally. For the anatomical group, the ABG (Stryker) prosthesis was used as a reference. All the three implants were designed to fit and fill the canal of the femur which has been reconstructed virtually from Computed Tomography (CT) image datasets. All implants have the same length and a homogeneous surface structure and surface finish throughout.
The implants were then positioned inside the femoral canals and the necks of the implants were angulated according to the anteversion angles of the intact femur (Fig. 1). The stems were assigned a linear isotropic material properties resembling titanium alloy (110 GPa), whilst the properties of the bone was assigned according to the grey level values of the CT dataset. An in-house algorithm ${ }^{[7]}$ was used to correlate the grey-level of the CT images using the apparent density through cubic correlation proposed by Carter and Hayes ${ }^{[8]}$. This relationship was based on the assumption that cancellous and cortical bones are simply at different ends of a continuous spectrum.

Perfect bone-implant contact was assumed initially with the coefficient of friction set to 0.4 and an interference fit of $0.1 \mathrm{~mm}$. In order to predict and simulate unstable femoral components, bone-implant contacts were removed on elements with interface micromotion of more than 50 microns after the first iteration to simulate interfacial bone loss. The models were then loaded in the same physiological loading and the iterations continued until either a stable state micromotion was achieved or loosening was predicted.

Two of the most common physiological activitieswalking and stair cimbing were used in the analysis (Fig. 2). The dataset was obtained from the work of Bitsakos $^{[9]}$ and Duda ${ }^{[10-12]}$ in which muscle and joint forces for two physiological activities, walking and stair climbing, were measured using telemetry (Table 1).

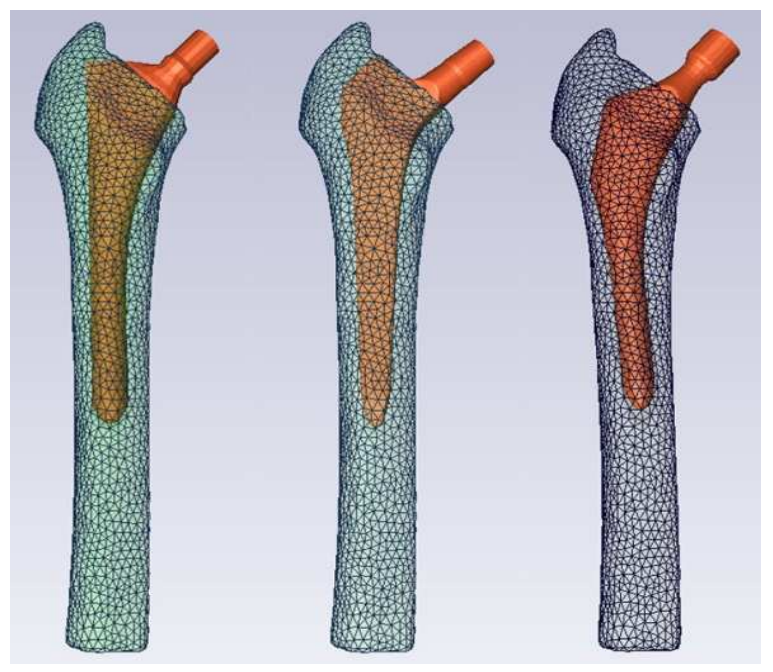

Fig. 1: The three models of cementless hip stems inside the femoral canal-straight cylinder (left), rectangular taper (middle) and anatomical (right) 
Am. J. Applied Sci., 6 (9): 1682-1689, 2009

Table 1: Maximum loading configurations in the 3rd phase (toe-off) from Bitsakos ${ }^{[9]}$

\begin{tabular}{lrrr}
\hline Force $(\mathrm{N})$ & $\mathrm{X}$ & $\mathrm{Y}$ & $\mathrm{Z}$ \\
\hline Joint contact force & -613.7 & -219.3 & 2868.7 \\
Gluteus maximus & 172.3 & -105.0 & -203.8 \\
Gluteus medius & 63.7 & -28.9 & -113.3 \\
& 85.0 & -32.2 & -97.4 \\
Gluteus minimus & 92.3 & -40.4 & -87.1 \\
& 25.4 & -0.7 & -51.6 \\
Illiopsoas & 30.2 & -14.4 & -46.8 \\
Piriformis & 43.2 & -18.6 & -33.2 \\
& 3.6 & 160.6 & -158.5 \\
& 110.5 & -70.1 & -22.4 \\
\hline
\end{tabular}

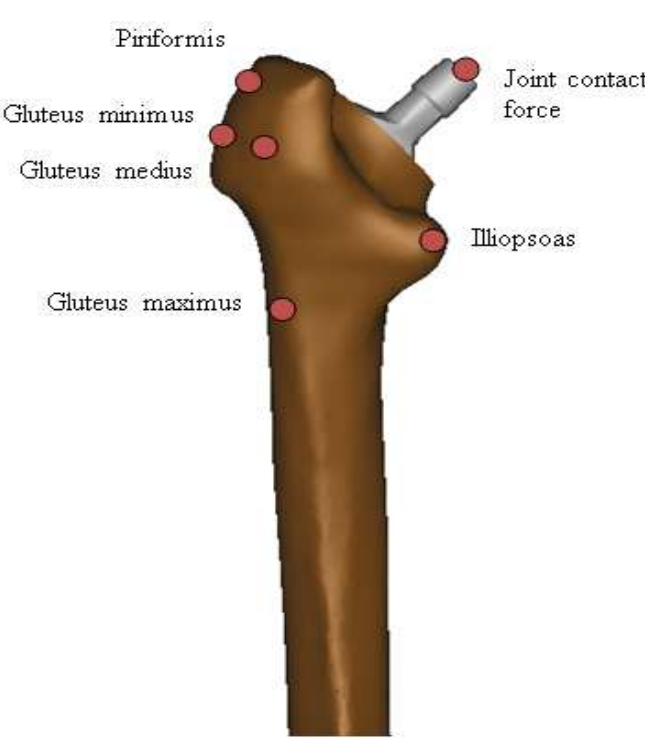

Fig. 2: Location of the muscles attachment used by ${ }^{[9]}$

An in-house experimentally validated computer algorithm ${ }^{[11]}$ was used to measure micromotion at the interface and predict instability of the stem. This algorithm calculates the displacement of the stem relative to the endosteal surface of the bone by subtracting displacement values between corresponding nodes at the interface. Non-linear contact analysis was used by assigning target and contact surfaces between the individual parts of the model. The constraint associated with no penetration is implemented by transforming the degrees of freedom of the contact node and applying a boundary condition to the normal displacement.

\section{RESULTS}

Figure 3 shows the magnitudes and distribution of micromotion for all three implants in both physiological walking and stair climbing. Large micromotions were found in the proximal areas and around the distal stem. The amount of surface areas with micromotion exceeded the threshold value of 50 microns were between $8-10 \%$ for all designs.
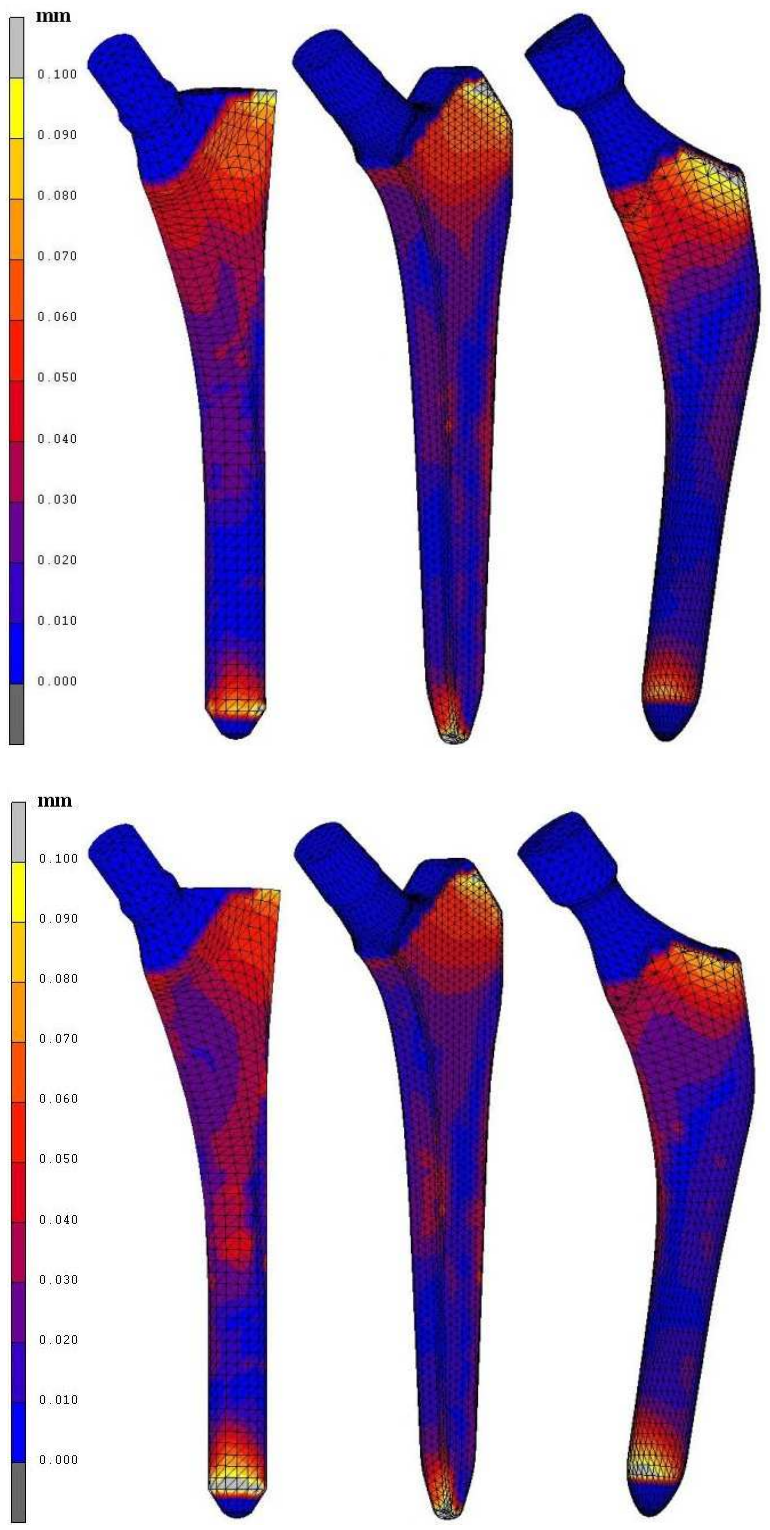

Fig. 3: Contour plots of micromotion for the cylindrical (left), the tapered (middle) and the anatomical (right) using Bitsakos gait loading (top) and Duda's stair-climbing loads (bottom) after the 1st iteration

After simulated interfacial bone loss, results were compared again (Fig. 4). In general, all designs were found to be stable with bone loss only increased slightly, up to $13 \%$. The anatomical design was found to be the most stable with a very small increase in surface area above 50 microns. The cylindrical design was the worst in stair climbing with an increase in unfeasible surface area from 9-13\%. The tapered design 


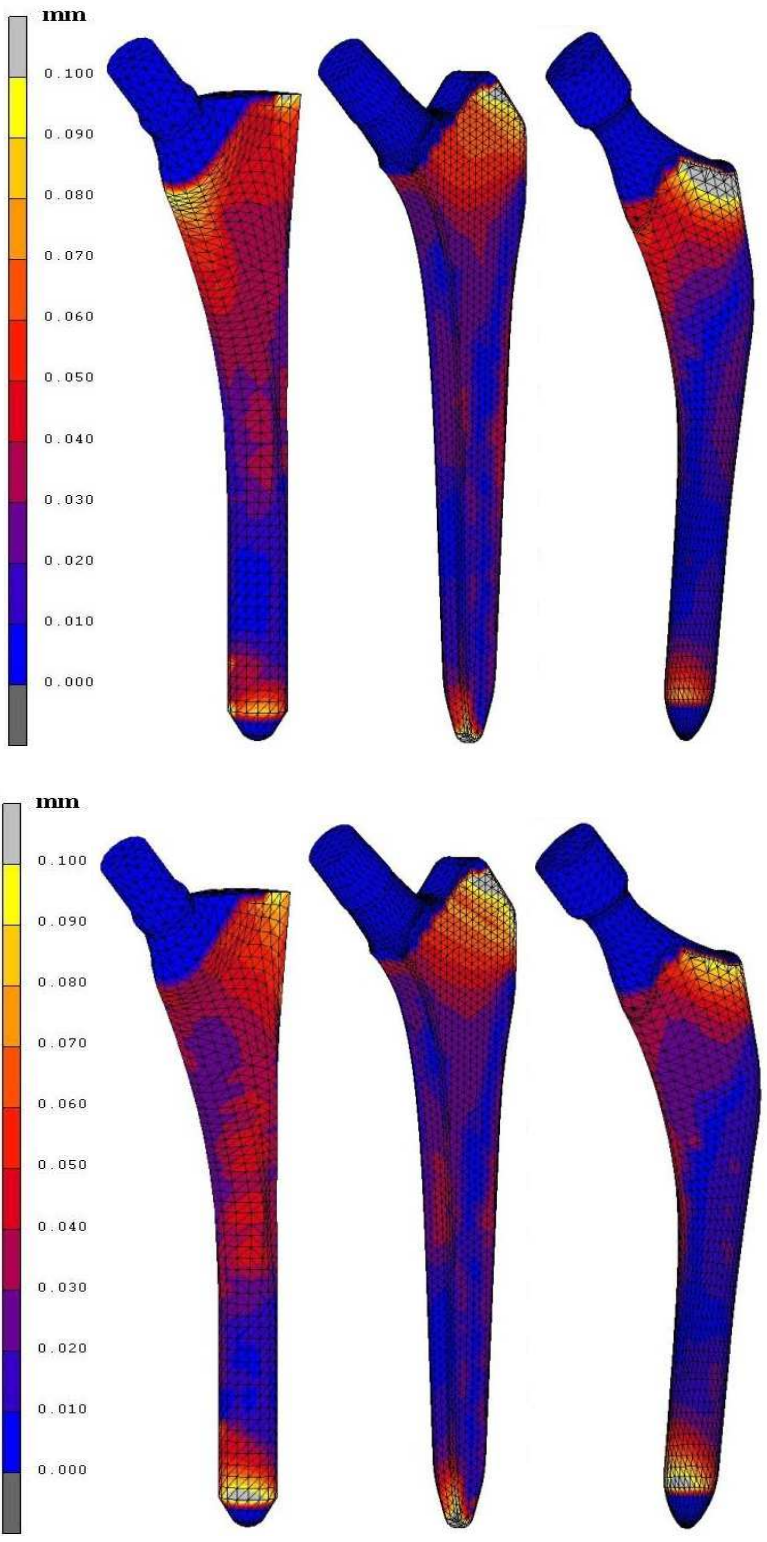

Fig. 4: Contour plots of micromotion for the cylindrical (left), the tapered (middle) and the anatomical (right) using Bitsakos gait loading (top) and Duda's stair-climbing loads (bottom) after simulated interfacial bone loss

was the worst in physiological walking where there was an increase from 8-10\%. Fig. 5 shows the reduction of the surface area unfeasible for bone growth.

\section{DISCUSSION}

The results showed that the three categories of hip stems, the cylindrical, the tapered and the anatomical,

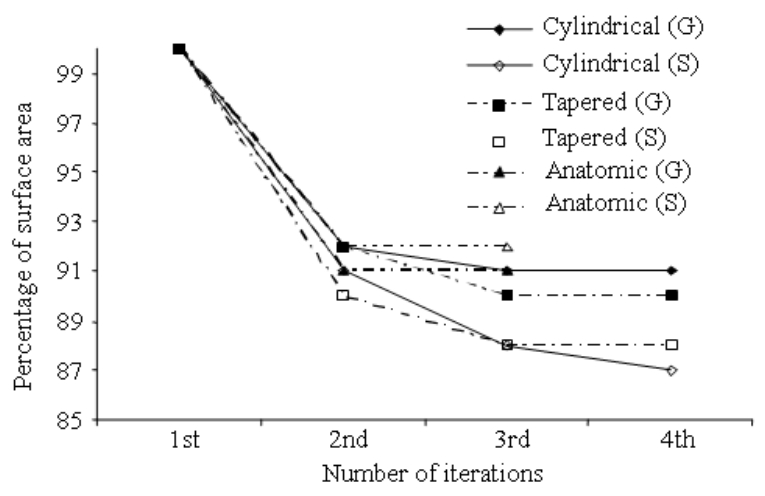

Fig. 5: Percentage of surface area with predicted bone growth for the cylindrical, the tapered and anatomical stem designs using Bitsakos gait

had similar distribution of micromotion and were all stable when bone loss was simulated. The results are in agreement with published results of actual hip stems belonging to these groups. The AML, the Alloclassic and the ABG are all implants with excellent survival rates in short-term, medium-term and long-term ${ }^{[14-26]}$.

The AML is one of the most widely used cementless stems with good clinical outcomes after hip arthroplasty ${ }^{[14]}$. The results are well-published covering patients with a wide range of ages. Sugiyama et al..$^{[15]}$ reported their 15 years clinical experience with the AML hip prosthesis. Out of 393 AML stems implanted only 6 have been revised, 3 of which were due to loosening. Another study ${ }^{[16]}$ reported a survival rate of $92 \%$ at 10.5 years with $88 \%$ of the patients had good or excellent clinical results. Kronick et al. ${ }^{[17]}$ reported a follow-up study of 88 AML stems inserted in patients under the age of 50 with a survival rate of 99 and $96 \%$ of which has bone ingrown, 3\% stable fibrous tissue and only $1 \%$ was found unstable.

The FE results were also in agreement with other follow-up studies in terms of predicting bone ingrowth. When solid initial fixation of the AML stem is achieved intraoperatively and radiographically, bone ingrowth reliably occurs whether or not the patient is allowed partial or full weight-bearing post surgery ${ }^{[18,19]}$. Dense cortical and cancellous bone ingrowth was found with strong attachment of the metal implant to the surrounding bone ${ }^{[20]}$. No slippage was found at the interface when the retrieved sample was tested under torsional and axial load. Another study reported that an average of $57 \%$ of the porous coated area of the stem had bone ingrowth ${ }^{[15]}$.

For the anatomical design, there are also follow-up reports confirming our FE predictions. The ABG hip stem has been reported to have excellent clinical and 
radiographic results at short-term ${ }^{[21,22]}$ and middle-term follow-up ${ }^{[23-25]}$. Other anatomical stem designs such as the APR-II and the Profile showed excellent clinical and radiographic results at 10 years follow-up, with no stems revised for aseptic loosening ${ }^{[26,27]}$. Proximal fixation through bone ingrowth was found in all stems and no patient reporting thigh pain after 3 years.

In vitro experimental comparison studies between a curved anatomical stem and a straight stem ${ }^{[28-30]}$ found that at low angles of flexion, the curved and straight stems demonstrated similar patterns of interface micromotion. However, at high torsional moments such as the one observed during stair climbing, the curved stem was found to be more stable than the straight stem. Our FE results, however, did not show a significant difference between the two designs at this physiological loading condition. The reason could be that in the FE models, a perfect fit was assumed with an interference of $0.1 \mathrm{~mm}$ throughout the surface of the stem. The FE results showed that the straight stem had $9 \%$ surface area in excess of the threshold limit of $50 \mu \mathrm{m}$ interface micromotion compared to the anatomical stem with $8 \%$. However, when the bone elements were adjusted to simulate bone loss, the area $\mathrm{f}^{[1]}$ or the straight stem increased to $12 \%$, but the anatomical stem maintained at $8 \%$. This showed that straight stems were more susceptible to micromotion during stair-climbing when a perfect fit at the interface was not achieved.

The Alloclassic, which has a tapered stem geometry, also showed good clinical outcome with a reported survival rate of $99.3-100 \%$ between 511 years $^{[31-33]}$. In one of the follow-up reports of the Alloclassic ${ }^{[34]}, 98 \%$ of the hips were rated good or excellent clinically at a median of 4 years. No stem was classified as definitely loose and no hips required revision. There was also no incidence of femoral osteolysis. Another study ${ }^{[35]}$ reported that only 3 out of 133 stems subsided 2-5 $\mathrm{mm}$ and one subsided 5-10 mm within the first year, but no progressive subsidence could be detected beyond this period. Effenberger et al. ${ }^{[36]}$ reported excellent results at 8 years for the Alloclassic with $83 \%$ showing no radiolucency and $17 \%$ showing radiolucency only proximally. A retrieval study of the Alloclassic $^{[37]}$ found that extensive bone-to-prosthesis apposition occurred at the interface along the stem between 6 weeks to 60 months. Other hip stem designs with tapered geometry have also shown excellent results at 5 years ${ }^{[38]}$ and 10 years ${ }^{[39-41]}$ post operatively.

In this study, the models representing the three groups have been modeled in such a way that a proper comparison could be made between them. The actual hip stem design, however, also has other important micro and macro features to enhance primary and secondary stability. The Alloclassic, for example, has a lateral flare feature-a proximal lateral expansion, which is designed to engage the lateral cortex of the femur in the metaphysis. It has been reported that this feature provides extra initial stability in cementless hip stems ${ }^{[42-43]}$. The ABG has unique semi-circular indentation macrofeatures on both its anterior and posterior sides. This feature can provide additional fixation strength proximally as the distal bone overreaming technique employed for this stem will only allow load transfer in the proximal region. Proximal tapered fins such as the one found in CLS stem and grooves were also used to provide primary and secondary stability.

\section{CONCLUSION}

Three types of cementless femoral stems were analyzed for stability using an in-house experimentally validated interface micromotion algorithm. Load simulating physiological activities of walking and stairclimbing was used and micromotion results were compared between them. Interfacial bone loss was simulated to better predict the stability of the stems. The results showed that the three types of femoral stems were stable under both physiological activities.

\section{ACKNOWLEDGEMENT}

This project has been supported by the Government research grant no. 01-01-06-SF0034.

\section{REFERENCES}

1. Healy, W.L., 2002. Hip implant selection for total hip arthroplasty in elderly patients. Clin. Orthop. Relat. $\quad$ Res., 405: 54-64. http://www.ncbi.nlm.nih.gov/pubmed/12461356

2. Mallory, T.H., A.V. Lombardi, J.R. leith, H. Fujita and J.F. Hartman et al., 2001. Minimal 10-year results of a tapered cementles femoral componenet in hip arthroplasty. J. Arthroplasty, 16: 49-54. DOI: 10.1054/arth.2001.28721

3. Howard, J.L., A.J. Hui, R.B. Bourne, R.W. McCalden, S.J. macdonald and C.H. Rorabeck, 2004. A quantitative analysis of bone support comparing cementless tapered and distal fixation total hip replacements. J. Arthroplasty, 19: 266-273. DOI: 10.1016/j.arth.2003.09.011

4. Kim, Y.H. and V.E. Kim, 1994. Cementless porous-coated anatomic medullary locking total hip prostheses. J. Arthroplasty, 9: 243-252. http://www.ncbi.nlm.nih.gov/pubmed/8077972 
5. Reitman, R.D., R. Emerson, L. Higgins and W. Head, 2003. Thirteen year results of total hip arthroplasty using a tapered titanium femoral componenet inserted without cement in patients with type $\mathrm{C}$ bone. J. Arthroplasty, 18: 116-121. DOI: 10.1016/S0883-5403(03)00344-9

6. Kim, Y.H., S.H. Oh and J.S. Kim, 2003. Comparison of porous-coated titanium femoral stems with and without hydroxyapetite coating. J. Bone Joint Surg. Am., 85: 109-114. http://www.ejbjs.org/cgi/reprint/85/1/109

7. Hopkins, A.R., U.N. Hansen, A.A. Amis, M. Taylor, N. Gronau and C. Anglin, 2005. Finite element modelling of glenohumeral kinematics following total shoulder arthroplasty. J. Biomech., J. Biomech., 39: 2476-2483. DOI: 10.1016/j.jbiomech.2005.07.031

8. Carter, D.R. and W.C. Hayes, 1977. The compressive behavior of bone as a two-phase porous structure. J. Bone Joint Surg. Am., 59: 954-962. http://www.ejbjs.org/cgi/reprint/59/7/954?maxtoshow=\& HITS $=10 \&$ hits $=10 \&$ RESULTFORMAT $=\&$ fulltext $=\% 22$ The+compressive+behaviour+of+bone+as+a+twophase \&andorexactfulltext $=$ and \&searchid $=1 \&$ FIRSTIND $\mathrm{EX}=0$ \&sortspec $=$ relevance\&resourcetype $=$ HWCIT

9. Bitsakos, C., J. Kerner, I. Fisher and A. Amis, 2005. The effect of muscle loading on the simulation of bone remodelling in the proximal femur. J. Biomech., 38: 133-139. DOI: 10.1016/j.jbiomech.2004.03.005

10. Duda, G.N., E. Schneider and E.Y.S. Chao, 1997. Internal forces and moments in the femur during walking. J. Biomech., 30: 933-941. DOI: 10.1016/S0021-9290(97)00057-2

11. Duda, G.N., D. Brand, S. Freitag, W. Lierse and E. Schneider, 1996. Variability of femoral muscle attachments. J. Biomech., 29: 1185-1190. DOI: 10.1016/0021-9290(96)00025-5

12. Duda, G.N., M. Heller, J. Albinger, O. Schulz, E. Schneider and L. Claes, 1998. Influence of muscle forces on femoral strain distribution. J. Biomech., 31: 841-846. DOI: 10.1016/S00219290(98)00080-3

13. Abdul-Kadir, M.R., U. Hansen, R. Klabunde, D. Lucas and A. Amis, 2007. Finite element modeling of primary hip stem stability: The effect of interference fit. J. Biomech., 41: 587-594. DOI: 10.1016/j.jbiomech.2007.10.009

14. Chess, D.G., R.W. Grainger, T. Phillips, Z.D. Zarzour and B.R. Sheppard, 1996. The cementless anatomic medullary locking femoral component: An independent clinical and radiographic assessment. Can. J. Surg., 39: 389-392. http://www.cma.ca/index.cfm/ci_id/35203/la_id/1. htm
15. Sugiyama, H., L.A. Whiteside, C.A. Engh and T. Otani, 1994. Late mechanical stability of the proximal coated AML prosthesis. Orthopedics, 17: 583-588. http://www.ncbi.nlm.nih.gov/pubmed/7937372

16. Nercessian, O.A., W.H. Wu and H. Sarkissian, 2001. Clinical and radiographic results of cementless AML total hip arthroplasty in young patients. J. Arthroplasty, 16: 312-316. http://www.ncbi.nlm.nih.gov/pubmed/11307128

17. Kronick, J.L., M.L. Barba and W.G. Paprosky, 1997. Extensively coated femoral components in young patients. Clin. Orthopead. Relat Res., 344: 263-274.

http://www.ncbi.nlm.nih.gov/pubmed/9372777

18. Woolson, S.T. and N.S. Adler, 2002. The effect of partial or full weight bearing ambulation after cementless total hip arthroplasty. J. Arthroplasty, 17: 820-825. DOI: 10.1054/arth.2002.34809

19. Engh, C.A., J.D. Bobyn and A.H. Glassman, 1987. Porous-coated hip-replacement-the factors governing bone ingrowth, stress shielding and clinical-results. J. Bone Joint Surg. Br., 69: 45-55. http://www.jbjs.org.uk/cgi/reprint/69-B/1/45.pdf

20. Otani, T., L.A. Whiteside, S.E. White and D.S. Mccarthy, 1993. Effects of femoral component material properties on cementless fixation in total hip arthroplasty. A comparison study between carbon composite, titanium alloy, and stainless steel. J. Arthroplasty, 8: 67-74. http://www.ncbi.nlm.nih.gov/pubmed/8436992

21. Rossi, P., P. Sibelli, S. Fumero and E. Crua, 1995. Short-term results of hydroxyapatite-coated primary total hip-arthroplasty. Clin. Orthopead. Relat. $\quad$ Res., $\quad 310$ : 98-102. http://www.ncbi.nlm.nih.gov/pubmed/7641466

22. A.J. Tonino, L. Romanini, P. Rossi, M. Borroni and F. Greco et al., 1995. Hydroxyapatite-coated hip prostheses: Early results from an international study. Clin. Orthopaed. Related Res., 312: 211-225. http://cat.inist.fr/?aModele $=$ afficheN\&cpsidt $=3620$ 263

23. Garcia, A.C., G.J. Fernandez and A. Tonino, 1998. Rheumatoid arthritis and hydroxyapatite-coated hip prostheses-five-year results. J. Arthroplasty, 13: 660-667. http://www.ncbi.nlm.nih.gov/pubmed/9741443

24. Giannikas, K.A., R. Din, S. Sadiq and T.H. Dunningham, 2002. Medium-term results of the ABG total hip arthroplasty in young patients. J. Arthroplasty, $\quad 17$ : 184-188. DOI: 10.1054/arth.2002.29394 
25. Herrera, A., V. Canales, J. Anderson, C. Garcia-Araujo, A. Murcia-Mazon and A.J. Tonino, 2004. Seven to 10 years followup of an anatomic hip prosthesis: An international study. Clin. Orthop. Relat. Res., 423: 129-137. http://www.ncbi.nlm.nih.gov/pubmed/15232438

26. Kim, Y.H., S.H. Oh and J.S. Kim, 2003. Primary total hip arthroplasty with a second-generation cementless total hip prosthesis in patients younger than fifty years of age. J. Bone Joint Surg. Am., 85: 109-114. http://www.ejbjs.org/cgi/reprint/85/1/109

27. Kang, J.S., L.D. Dorr and Z.N. Wan, 2000. The effect of diaphyseal biologic fixation on clinical results and fixation of the APR-II stern. J. Arthroplasty, 15: 730-735. DOI: 10.1054/arth.2000.9057

28. Berzins, A., D.R. Sumner, T.P. Andriacchi and J.O. Galante, 1993. Stem curvature and load angle influence the initial relative bone-implant motion of cementless femoral stems. J. Orthop. Res., 11: 758-769. DOI: 10.1002/jor.1100110518

29. Hua, J. and P.S. Walker, 1994. Relative motion of hip stems under load-an in vitro study of symmetrical, asymmetrical and custom asymmetrical designs. J. Bone Joint Surg. Am., 76: 95-103.

http://www.ejbjs.org/cgi/reprint/76/1/95

30. Callaghan, J.J., C.S. Fulghum, R.R. Glisson and S.K. Stranne, 1992. The effect of femoral stem geometry on interface motion in uncemented porous-coated total hip prostheses. Comparison of straight-stem and curved-stem designs. J. Bone Joint Surg. Am., 74: 839-848. http://www.ejbjs.org/cgi/reprint/74/6/839?maxtosh ow $=\&$ HITS $=10 \&$ hits $=10 \&$ RESULTFORMAT $=\& f$ ullext $=$ The + Effect + of + Femoral + Stem+Geometry +on+Interface+Motion+in+Uncemented+Porous-

Coated+Total+Hip+Prostheses+\&andorexactfulltex $\mathrm{t}=$ and \&searchid=1\&FIRSTINDEX $=0 \&$ sortspec $=$ re levance\&resourcetype $=$ HWCIT

31. Delaunay, C., C. Cazeau and A.I. Kapandji, 1998. Cementless primary total hip replacement. Int. Orthop., 22: 1-5. DOI: 10.1007/s002640050198

32. Pieringer, H., V. Auersperg, W. Griessler and N. Bohler, 2003. Long-term results with the cementless alloclassic brand hip arthroplasty system. J. Arthroplasty, 18: 321-328. DOI: 10.1054/arth.2003.50045
33. Pieringer, H., G. Labek, V. Auersperg and N. Bohler, 2003. Cementless total hip arthroplasty in patients older than 80 years of age. J. Bone Joint Surg. Br., 85: 641-645. http://www.jbjs.org.uk/cgi/reprint/85B/5/641 ? maxtoshow $=\& H I T S=10 \&$ hits $=10 \&$ RESU LTFORMAT $=\&$ author $1=$ Pieringer $\&$ fulltex $\mathrm{t}=$ Ceme ntless+total+hip+arthroplasty+in+patients+older+t han+80+years+of+age\&andorexactfulltext=and\&s earchid=1\&FIRSTINDEX=0\&sortspec=relevance \&resourcetype $=$ HWCIT

34. Huo, M.H., R.P. Martin, L.E. Zatorski and K.J. Keggi, 1995. Total hip arthroplasty using the Zweymuller stem implanted without cement. A prospective study of consecutive patients with minimum 3-year follow-up period. J. Arthroplasty, 10: 793-799. http://www.ncbi.nlm.nih.gov/pubmed/8749763

35. Delaunay, C., F. Bonnomet, J. North, D. Jobard, C. Cazeau and J.F. Kempf, 2001. Grit-blasted titanium femoral stem in cementless primary total hip arthroplasty-A 5-to 10-year multicenter study. J. Arthroplasty, 16: 47-54. DOI: 10.1054/arth.2001.17940

36. Effenberger, H., T. Ramsauer, G. Bohm, G. Hilzensauer, U. Dorn and F. Lintner, 2002. Successful hip arthroplasty using cementless titanium implants in rheumatoid arthritis. Arch. Orthopaed. Trauma Surg., 122: 80-87. DOI: 10.1007/s004020100320

37. Lester, D.K., 1997. Cross-section radiographic analysis of 10 retrieved titanium alloy press-fit femoral endoprostheses. J. Arthroplasty, 12: 930-937. http://www.ncbi.nlm.nih.gov/pubmed/9458259

38. Keisu, K.S., F. Orozco, J.D. McCallum, G. Bissett and W.J. Hozack et al., 2001. Cementless femoral fixation in the rheumatoid patient undergoing total hip arthroplasty: Minimum 5-year results. J. Arthroplasty, 16: 415-421. DOI: 10.1054/arth.2001.23506

39. Eingartner, C., R. Volkmann, E. Winter, F. Maurer and G. Sauer et al., 2000. Results of an uncemented straight femoral shaft prosthesis after 9 years of followup. J. Arthroplasty, 15: 440-447. DOI: $10.1054 /$ arth.2000.5265

40. Park, M.S., B.W. Choi, S.J. Kim and J.H. Park, 2003. Plasma spray-coated Ti femoral component for cementless total hip arthroplasty. J. Arthroplasty, 18: 626-630. DOI: 10.1016/S08835403(03)00203-1

41. Reitman, R.D., R. Emerson, L. Higgins and W. Head, 2003. Thirteen year results of total hip arthroplasty using a tapered titanium femoral component inserted without cement in patients with type $\mathrm{C}$ bone. J. Arthroplasty, 18: 116-121. DOI: 10.1016/S0883-5403(03)00344-9 
42. Leali, A., J. Fetto, H. Insler and D. Elfenbein, 2002. The effect of a lateral flare feature on implant stability. Int. Orthop., 26: 166-169. DOI: 10.1007/S00264-002-0355-3

43. Effenberger, H., A. Heiland, T. Ramsauer, W. Plitz and U. Dorn, 2001. A model for assessing the rotational stability of uncemented femoral implants. Arch. Orthop. Trauma Surg., 121: 60-64. DOI: $10.1007 / \mathrm{s} 004020000215$
44. Gortz, W., U.V. Nagerl, H. Nagerl and M. Thomsen, 2002. Spatial micromovements of uncemented femoral components after torsional loads. J. Biomech. Eng., 124: 706-713. DOI: $10.1115 / 1.1517565$ 